\title{
Eddy diffusivity derived from drifter data for dispersion model applications
}

\author{
Michela De Dominicis • Giovanni Leuzzi • Paolo Monti • \\ Nadia Pinardi • Pierre-Marie Poulain
}

Received: 15 September 2011 / Accepted: 20 July 2012 /Published online: 18 August 2012

(C) The Author(s) 2012. This article is published with open access at Springerlink.com

\begin{abstract}
Ocean transport and dispersion processes are at the present time simulated using Lagrangian stochastic models coupled with Eulerian circulation models that are supplying analyses and forecasts of the ocean currents at unprecedented time and space resolution. Using the Lagrangian approach, each particle displacement is described by an average motion and a fluctuating part. The first one represents the advection associated with the Eulerian current field of the circulation models while the second one describes the sub-grid scale diffusion. The focus of this study is to quantify the sub-grid scale diffusion of the Lagrangian models written in terms of a horizontal eddy diffusivity. Using a large database of drifters released in different regions of the Mediterranean Sea, the Lagrangian sub-grid scale diffusion has been computed, by considering different regimes when averaging statistical quantities. In addition, the real drifters have been simulated using a
\end{abstract}

Responsible Editor: Christophe Maisondieu

This article is part of the Topical Collection on Advances in Search and Rescue at Sea

M. De Dominicis $(\bowtie)$

Istituto Nazionale di Geofisica e Vulcanologia,

Viale Aldo Moro 44, 6th floor,

40128 Bologna, Italy

e-mail: michela.dedominicis@bo.ingv.it

G. Leuzzi $\cdot$ P. Monti

DICEA, "La Sapienza” University of Rome,

Rome, Italy

N. Pinardi

Corso di Scienze Ambientali, University of Bologna,

Ravenna, Italy

P.-M. Poulain

OGS, Istituto Nazionale di Oceanografia e di Geofisica

Sperimentale,

Trieste, Italy trajectory model forced by OGCM currents, focusing on how the Lagrangian properties are reproduced by the simulated trajectories.

Keywords Drifter · Lagrangian statistics · Diffusivity · Lagrangian models $\cdot$ Marine turbulence

\section{Introduction}

The prediction of particle transport in the ocean has become possible thanks to the increased numerical accuracy and availability of numerical ocean analyses and re-analyses (Castanedo et al. 2006; Coppini et al 2010). In the study of tracer dispersion, the simplest parameterization is obtained using "scale separation", by assuming the scales of the turbulence are infinitesimal compared with the scales of the mean field (Taylor 1921). Under this assumption, the evolution of a passive tracer can be approximated by an advection-diffusion equation, which describes the balance of the mean concentration, $C$, as for molecular diffusion, i.e. it is the advection-diffusion equation replaced by an "eddydiffusivity" coefficient:

$\frac{\partial C}{\partial t}+\mathbf{U} \cdot \nabla C=\nabla \cdot(\mathbf{K} \nabla C)$

where $\mathbf{U}=(U, V, W)$ represents the mean velocity field vector and $\mathbf{K}$ is the eddy diffusivity tensor which parameterizes the turbulence or the unresolved scales in the Eulerian framework.

An equivalent solution of the Eq. 1 can be obtained by integrating Lagrangian trajectories simulated by random walk processes. The Lagrangian method can represent the tracer transport more easily than the Eulerian one because the computational cost is concentrated only where the particles are located. 
In recent years, Lagrangian methods have been used extensively in the marine environmental modelling. A review on the Lagrangian stochastic model applied in marine environment can be found in Monti and Leuzzi (2010). In this class of models, the trajectory of individual particles is described by a velocity due to the "mean" flow and a velocity associated with the fluctuating or sub-grid scale diffusion processes. The basic stochastic model is the random walk model that is written as:

$$
\left(\begin{array}{l}
\mathrm{d} x(t) \\
\mathrm{d} y(t) \\
\mathrm{d} z(t)
\end{array}\right)=\left(\begin{array}{c}
U(\mathbf{x}, t) \\
V(\mathbf{x}, t) \\
W(\mathbf{x}, t)
\end{array}\right) \mathrm{d} t+\left[\begin{array}{ccc}
\sqrt{2 K_{x}} & 0 & 0 \\
0 & \sqrt{2 K_{y}} & 0 \\
0 & 0 & \sqrt{2 K_{z}}
\end{array}\right]\left(\begin{array}{c}
\Delta \mu_{x} \\
\Delta \mu_{y} \\
\Delta \mu_{z}
\end{array}\right)
$$

where $\mathrm{d} x, \mathrm{~d} y, \mathrm{~d} z$ are the particle displacements, $\mathrm{d} t$ is the time step, $K_{x}, K_{y}, K_{z}$ are the diagonal components of the eddy diffusivity tensor and $\Delta \mu_{x}, \Delta \mu_{y}, \Delta \mu_{z}$, are incremental random forcings that represent a Wiener process with independent increments, zero mean and variance equal to $\mathrm{d} t$. This simple stochastic model is valid only for homogeneous turbulence and for time scales much larger than the integral time scale (Hunter et al. 1993).

The applicability of the advection-diffusion equation is often questionable for oceanographic problems, as noticed by a number of authors (e.g., Davis 1987; Zambianchi and Griffa 1994; Falco et al. 2000). This is due to the fact that the flow decomposition may be not well defined, so that the scale separation hypothesis does not strictly hold, especially when the large-scale flow is highly inhomogeneous and nonstationary. This has important consequences for eddy diffusivity calculation methods applied over the sea, where the scale separation may be difficult to establish. However, it is generally accepted the validity of the scale separation hypothesis (LaCasce 2008). The point to be solved is what time scale should be used to separate the mean from the residuals. Despite this restriction, the advection diffusion equation is widely used in oceanography, mainly because it is simple and straight forward to implement (Griffa 1996; Falco et al. 2000). Generalizations of the advection diffusion equation (generalized "K-models"), where the scale separation hypothesis is relaxed, are available in the literature (Davis 1987), but they are not frequently used in practical applications because of the difficulties in their implementation.

In principle, the eddy diffusivity is an observable quantity and Lagrangian data are especially suitable to estimate it (e.g., Colin de Verdiere 1983; Swenson and Niiler 1996). In the last decades, in order to understand Lagrangian motion at sea, several studies (e.g., Poulain and Niiler 1989; Falco et al. 2000; Poulain 2001; Maurizi et al. 2004; Ursella et al.
2006; Poulain and Zambianchi 2007; Sallée et al. 2008) analysed surface drifter data and computed the mean and fluctuating velocity components and diffusivities. The theoretical framework used in those analyses is Taylor's (1921) theory of stationary and homogenous turbulence, but even inside relatively small subdomains, different regimes of dispersion may exist, because of the huge variability of Lagrangian behaviours. The computation of statistical parameters by means of simple and unconditioned means among Lagrangian trajectories experiencing different flow regimes may give rise to misleading results. To avoid mixture of different regimes computing statistical quantities, different methods have been developed. Berloff and McWilliams (2003) proposed to use stochastic models in which the decorrelation parameters vary with statistical properties. Veneziani et al. (2004) separated the Lagrangian trajectories in homogeneous classes by considering as screening index the trajectory mean vorticity, while Rupolo (2007) used the ratio between the acceleration and velocity time scale.

Most of the Lagrangian stochastic and oil spill models proposed in the literature use as input data the mean velocity fields provided by Eulerian hydrodynamics models based on different horizontal diffusivity parameterizations, sometimes connected to turbulence closure sub-models. Recently, due to the relatively high grid resolution, Eulerian hydrodynamics models use very low explicit diffusivities leaving only the implicit finite difference numerical schemes diffusion. The fluctuating part of the Lagrangian model (Eq. 2) accounts for the turbulence and those sub-grid scale processes not already solved by the Ocean General Circulation Models (OGCMs). The evaluation of the eddy diffusivity to be used in Eq. 2 is still an open question, which will be also addressed in this paper.

In light of the above, the major purpose of this work is to set up a method to calculate the eddy diffusivity on the basis of the drifter datasets and to establish the criteria to determine whether or not the calculated diffusivity can be used as input in Lagrangian stochastic and oil spill models. In a recent work, Döös et al. (2011) found the diffusivity value, to be put in Eq. 2, from modelled drifters trajectories simulated using an eddy permitting OGCM of $25 \mathrm{~km}$ of resolution. There is now the need to investigate the sensitivity of eddy diffusivity parameterization to be put in Lagrangian models to different model resolution, in order to investigate how much sub-grid parameterization would be needed with high horizontal resolution models and how different geographical regions or dynamical regimes can affect the Lagrangian sub-grid diffusion parameterization.

In this work, we tested different methods to estimate the mean flow, the diffusivity and time scales, starting from the basic method applied in the pioneer work of Colin de Verdiere (1983) to the regime separations analysis developed in the more recent works of Rupolo (2007). 
In addition, the real drifters have been simulated using a trajectory model forced by OGCM currents, in order to evaluate the discrepancies between the horizontal diffusivity and integral time scales calculated from the real drifters and the OGCM Lagrangian properties. The simulations have been done using the daily and hourly mean currents provided by the Mediterranean Forecasting System (MFS) (Pinardi et al. 2003); (Pinardi and Coppini 2010), focusing on how the Lagrangian properties depend on the temporal resolution of the velocity fields.

In this work, all the calculations were done using high temporal resolution data (hourly sampling), that were not used in the previous works. Two drifter datasets will be used: the first collected in the Liguro-Provencal basin (Poulain et al. 2012) and the second in the Adriatic Sea (Ursella et al. 2006), thus sampling very different current regimes. The Ligurian Sea is a deep basin, characterized by a Rossby radius of deformation of $10 \mathrm{~km}$ (Grilli and Pinardi 1998), so eddies are of the order of $20-30 \mathrm{~km}$ in diameter, and large continental slope currents encircle cyclonically the basin. The Adriatic Sea is instead a continental shelf basin with western boundary intensified coastal currents, semipermanent gyres and a Rossby radius of deformation of 5 km (Paschini et al. 1993; Grilli and Pinardi 1998), thus smaller mesoscale eddies.

The work is organized as follows. In Section 2, the drifter datasets are presented and in Section 3 the methods used to determine both the horizontal diffusivity and the integral time scale are described. Section 4 presents the values of Lagrangian sub-grid scale diffusivity. Section 5 shows the estimates of horizontal diffusivity and the integral time scale using simulated trajectories and Section 6 offers some discussion and conclusions.

\section{Drifter observations}

The data used in this work derive from surface drifters observations in the Liguro-Provençal basin (a sub-basin of the north-western Mediterranean Sea) and in the Adriatic Sea (Eastern Mediterranean Sea).

The drifter design is similar to that used in the COastal Dynamics Experiment (CODE) in the early 1980s (Davis 1985). The drifters are equipped with the standard Doppler-based Argos tracking and telemetry, which has an accuracy of 300-1,000 $\mathrm{m}$ and the positions are available 6-12 times per day. These drifters can also be localized by the Global Positioning System (GPS) and the data are telemetered via the Argos system. GPS locations have an accuracy of $10 \mathrm{~m}$ and the CODEGPS were programmed to sample position every hour. Quality control of the drifter positions has been carried out with automatic statistical and manual procedure.
Detailed explanation of the data editing can be found in Ursella et al. (2004) and Ursella et al. (2006).

The Ligurian Sea drifters were deployed in small clusters $(1 \mathrm{~km})$ of three to five units at a single location (Fig. 1a) in the vicinity of the ODAS buoy $\left(9.17^{\circ} \mathrm{E}\right.$ $\left.43.79^{\circ} \mathrm{N}\right)$. One central drifter was released in the vicinity of the ODAS buoy and the other four drifters $500 \mathrm{~m}$ far from the central buoy in direction North, South, East and West. In the Ligurian Sea, the surface drifters were deployed in May and June 2007 and in September and October 2008. Some drifters stranded on the Italian and French coasts and were successfully redeployed. Considering that some drifters failed transmitting right after deployments and others were successfully recovered and redeployed, a total of 32 drifters, equipped with both GPS and Argos tracking system, were available for the determination of the turbulent parameters.

In the Adriatic Sea, the surface drifters were deployed in the Northern and Central Adriatic between September 2002 and March 2004. Fifty-five of the total drifters deployed (188 drifters, including the drifter recovered and redeployed) were localized every hour using the GPS and have been used in this work. The Northern and Central Adriatic were well sampled with a maximum of drifter density in the northernmost part of the basin decreasing southward (Ursella et al. 2006) (Fig. 1b).

\section{Methods}

The diffusivity, $K_{i}$, and the Lagrangian integral time scale, $T_{i}$, components (where $i=1,2,3$ refer to the $x, y, z$ Cartesian axis, respectively), can be determined using the (Taylor 1921) theory, which allows to calculate the Lagrangian properties starting from the observed drifters velocity (see Appendix A) assuming stationary and homogenous turbulence. Using the quality-checked drifter data, the drifter surface velocities have been calculated using a finite difference scheme between successive drifter positions (hourly data).

From the drifter velocities, the mean flow $\overline{\mathbf{u}}$ and the turbulent $\mathbf{u}^{\prime}$ components can be estimated. The diffusivity and the turbulent time scale take different values depending on the method used in the calculation of the mean flow velocity.

If the space or time scales of $\overline{\mathbf{u}}$ are not correctly evaluated, they will deteriorate the $\mathbf{u}^{\prime}$ statistics and as a consequence the estimates of $K_{i}$ and $T_{i}$. In general, it is believed that $\overline{\mathbf{u}}$ is a good approximation of the Eulerian fields, or mean fields, simulated by the ocean circulation models. 
Fig. 1 Position diagram of the drifter data: a Ligurian Sea; $\mathbf{b}$ Adriatic Sea a



b

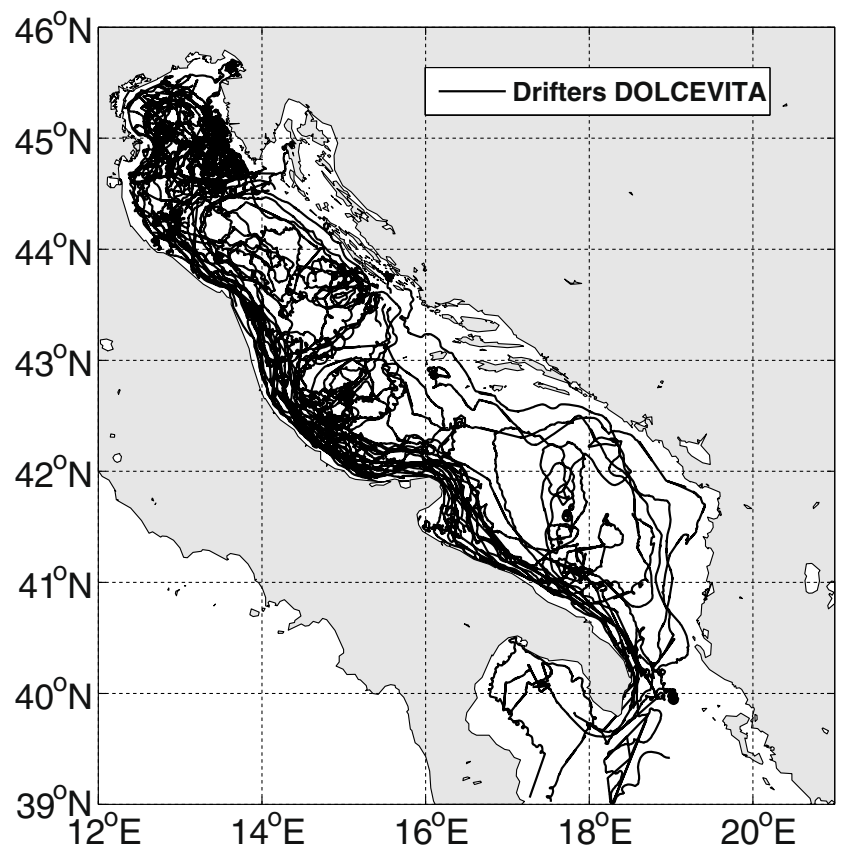

In order to correctly evaluate the turbulence effects, the drifter velocity should assume a separation in time scales or, equivalently, a gap in the velocity frequency spectrum. The correct time scale for estimating the mean velocity to be used in the fluctuating velocity calculation could be estimated with some precision only if an energy gap exists between the low-frequency fluctuations and the high frequency of the signal. All indications are that no such gap exists (Zang and Wunsch 2001). In our datasets, we have observed that this gap does not exist until the frequency of $1 \mathrm{~h}^{-1}$, by calculating and analyzing the energy spectra of the Adriatic and Ligurian Sea drifter data.

Although an energy gap was not detected, we have to assume a separation in time scales. Removing the mean velocity is complicated by the fact the means vary with the locations and depth. Such issues have been considered by Davis in a series of articles (Davis 1983, 1985, 1987), where the general notion is that the velocities from different floats 
and times are averaged together over defined geographical regions ("bins") to estimate the Eulerian mean velocities.

His methodology has been widely applied to ocean data, and different bin sizes and even different bin shapes and orientations have been explored (Poulain and Niiler 1989; Falco et al. 2000; Poulain 2001; Ursella et al. 2006; Poulain and Zambianchi 2007). Improvements such as fitting the binned velocities with cubic splines (Bauer et al. 2002), or grouping a specified amount of data into spatially localized subsets using a "clustering" algorithm (Koszalka and LaCasce 2010) have been tested.

In this paper, the mean flow is calculated as a timeaveraged velocity (as already done by Rupolo (2007)) and we tested different eddy diffusivity calculation methods, by varying the averaging period.

The analysis of drifters data can be influenced by the non-homogenous character of the flow field and by the existence of different dispersion regimes. The drifter motion is affected by the non-homogeneous spatial and unsteady structure of the Eulerian velocity field. Thus, averaging among long trajectories that experience a variety of different flow regimes can lead to misleading results. In order to overcome this limitation, in addition to the classical approaches based on the assumption of flow field homogeneity and steadiness (Methods 1 and 2), we applied the Rupolo (2007) method to subdivide the dataset into classes of trajectories morphologically homogeneous and characterized by different regimes of dispersion (Method 3).

The choice of the coordinates system is expected to play a role in the calculation of the fluctuating component of the flow field and we have chosen to use a locally oriented Cartesian coordinate system with one of the axis oriented along the mean flow direction (Maurizi et al. 2004). The horizontal components of the velocity vector will be then represented by an along-current and an across-current component, indicated as $u_{/ /}$and $u_{\perp}$, respectively. Similarly, the diffusivity horizontal components (the horizontal components of the eddy diagonal tensor components) will be then indicated as $K_{/ /}(t)$ and $K_{\perp}(t)$, respectively.

Following the Taylor (1921) theory (Eq. A.4), the diffusivity can be calculated by the velocity variance:

$K_{/ /}(t)=\left\langle u^{\prime} /{ }^{2}\right\rangle T_{/ /}$

$K_{\perp}(t)=\left\langle u_{\perp}^{\prime}{ }^{2}\right\rangle T_{\perp}$

and as the time rate of change of the drifters displacement fluctuation $d^{\prime}$ respect to the average value:

$$
\begin{aligned}
& K_{/ /}(t)=\frac{1}{2} \frac{d}{d t}\left\langle d_{/ /}^{\prime 2}\right\rangle \\
& K_{\perp}(t)=\frac{1}{2} \frac{d}{d t}\left\langle d_{\perp}^{\prime 2}\right\rangle
\end{aligned}
$$

Method 1 In spite of the non-uniform nature of the observed data, we begin the analysis with the simplest assumption of homogeneity and steadiness of the flow field. The turbulent components $\left(u_{/ /,}^{\prime}, u_{\perp}^{\prime}\right)$ have been calculated as the difference between the hourly drifter velocities and the mean velocity calculated over the whole drifter trajectory. The autocorrelation function has been computed using (A.1). The integral time scale components $\left(T_{/ /}, T_{\perp}\right)$ have been calculated as the integral of the velocity autocorrelation up to the first zero-crossing (see A.2). The diffusivity components $\left(K_{/ /}, K_{\perp}\right)$ have been computed using (3). The length of the drifter tracks can vary between 7 days and 4 months. Thus, if we consider a mean drifter velocity of $0.1-0.2 \mathrm{~m} / \mathrm{s}$, the corresponding displacement during the drifters life is between 60 and 2,000 km.

Method 2 Assuming a decorrelation time scale of the entire drifter tracks equal to 7 days, positions more than 7 days apart are independent and can be set to be the origin of independent tracks. Thus, the number of degrees of freedom was increased by considering sub-tracks whose origins are taken every 7 days. The calculation has been done along the 32 Ligurian Sea original trajectories, giving a total of 169 sub-tracks. The turbulent components $\left(u^{\prime} / /\right.$, $u_{\perp}^{\prime}$ ) have been calculated as the difference between the hourly drifter velocity and the average of the drifter velocity calculated over the drifter subtrack. The diffusivity components $\left(K_{/ / /}, K_{\perp}\right)$ have been computed using both Eqs. (3) and (4). Because the considered drifter sub-tracks can vary between 7 days and 4 months, the results will refer to structures with spatial scales less than $2,000 \mathrm{~km}$.

Method 3 We decided to subdivide the original drifter trajectories into non-overlapping segments 7, 4 and 1 day long. Obviously, reducing the length of the segments will generate problems with the autocorrelation function calculation: for large lag, the autocorrelation should be computed by averaging over only a limited number of pairs of observations and should be very noisy. In contrast, increasing the length compromises the homogeneity and steadiness assumption. The residual velocities are obtained by considering a mean velocity over a time window of 7, 4 and 1 day. We will separate the trajectories in different classes characterized by different values of $y$, computed for each trajectory segment as follows:

$y=\frac{T_{a}}{T_{v}}$ 
where $T_{\mathrm{a}}$ and $T_{\mathrm{v}}$ are, respectively, the acceleration and velocity time scales obtained by Rupolo (2007):

$T_{\mathrm{v}}=\frac{T_{\mathrm{L}}+\sqrt{T_{\mathrm{L}}^{2}-4 \frac{\sigma^{2} \mathrm{U}}{\sigma^{2}}}}{2}$

$T_{\mathrm{a}}=\frac{T_{\mathrm{L}}-\sqrt{T_{\mathrm{L}}^{2}-4 \frac{\sigma^{2} \mathrm{U}}{\sigma_{\mathrm{A}}^{2}}}}{2}$

where for each trajectory $T_{\mathrm{L}}=(1 / 2)\left(T_{/ /}+T_{\perp}\right)$. Here, $\sigma_{\mathrm{U}}^{2}=(1 / 2)\left(\sigma_{\mathrm{U} / /}^{2}+\sigma_{\mathrm{U}_{\perp}}^{2}\right)$ is the velocity variance and $\sigma_{\mathrm{A}}^{2}=(1 / 2)\left(\sigma_{\mathrm{A} / /}^{2}+\sigma_{\mathrm{A}_{\perp}}^{2}\right)$ the acceleration variance, computed from the velocity and acceleration time series. When $T_{\mathrm{L}}^{2}<4 \sigma_{\mathrm{U}}^{2} /$ $\sigma^{2}{ }_{\mathrm{A}}, T_{\mathrm{a}}$ and $T_{\mathrm{v}}$ (Eq. 6) are complex quantities. In this case, $\left|T_{\mathrm{a}}\right|=\left|T_{\mathrm{v}}\right|,|y|=1$ and the trajectory has an oscillatory behaviour. For a further characterization, the parameter $x$ is also calculated:

$x=\frac{\sqrt{4 \frac{\sigma^{2} \mathrm{U}}{\sigma^{2} \mathrm{~A}}-T_{\mathrm{L}}^{2}}}{T_{\mathrm{L}}}$

which represents the ratio between the oscillatory and memory time scales (Rupolo 2007). The trajectories will be then subdivided into four classes: $y<0.2$ (Class I), $0.4<y<0.8$ (Class II), $|y|=1, x<1$ (Class III) and $|y|=1, x>1$ (Class IV). Following Rupolo's (2007) classification, in Class I are grouped the trajectories characterized by large-scale variability, in Class II the trajectories show intermediate characteristics, meandering around large-scale structures, in Class III the trajectories are characterized by the presence of coherent Lagrangian structures and the drifters seem to jump between eddies of different size, in Class IV the trajectories are again characterized by the presence of coherent Lagrangian structures and rapidly whirl, but are trapped inside eddies with a well defined length scale (looping behaviour).

Our goal is to find a value of diffusivity to be used in Eq. 2, where the mean flow will be provided by OGCMs, which nowadays reach a resolution up to $1 \mathrm{~km}$. Assuming different averaging period and considering a mean drifter velocity of $0.1-$ $0.2 \mathrm{~m} / \mathrm{s}$, our results for $T_{\mathrm{i}}$ and $K_{\mathrm{i}}$, using 7, 4 and 1 day trajectory segments, refer to structures with spatial scales respectively of 60 $120,35-70$ and $9-17 \mathrm{~km}$. a

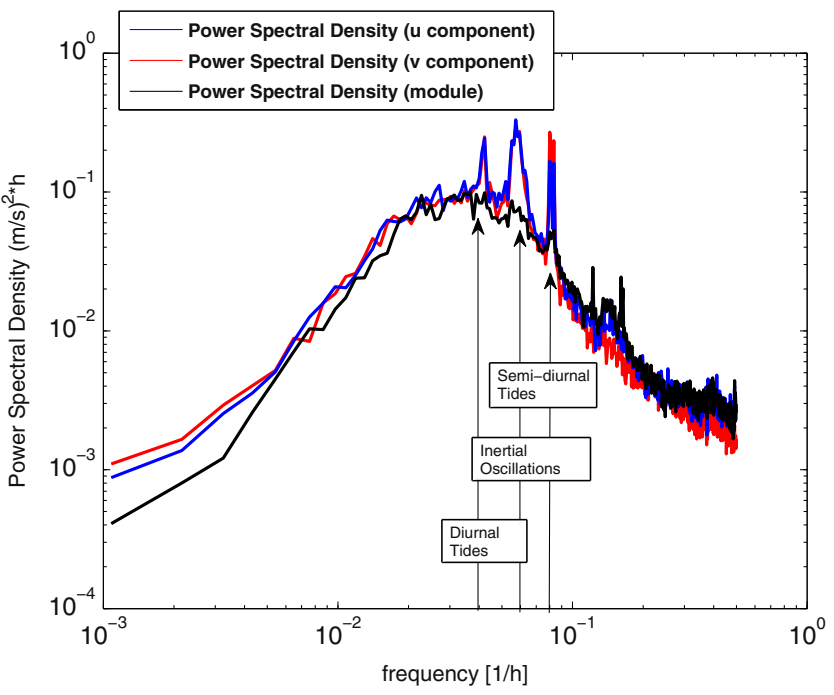

b

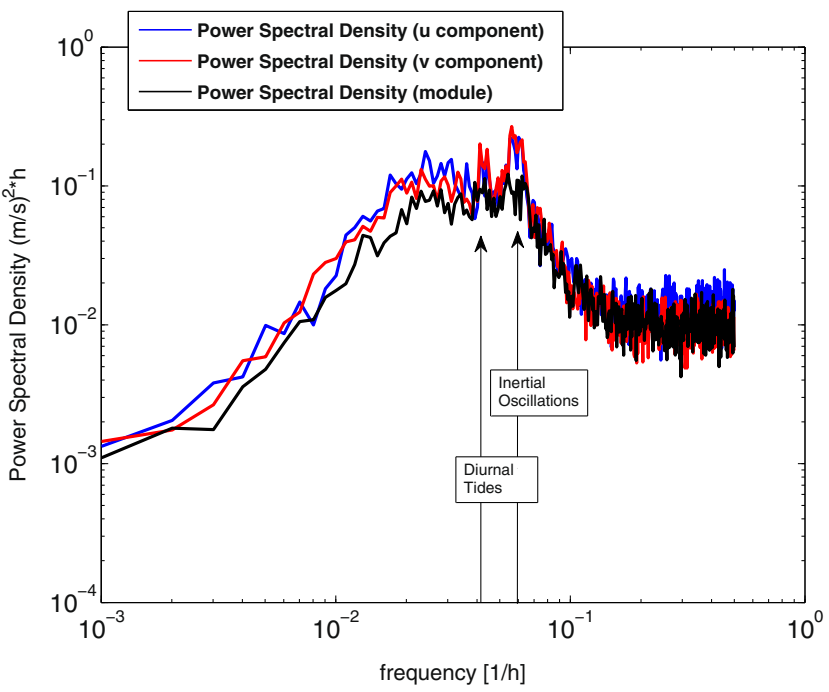

Fig. 2 Lagrangian spectra calculated from the drifters trajectories: a Adriatic Sea; b Ligurian Sea. The abscissa is in inverse of hours and the ordinate has the kinetic energy divided by the frequency (inverse of hours). $u$ and $v$ are the zonal and meridional velocity components

\section{Results}

\subsection{Energy spectra}

The energy spectra of the fluctuations are displayed in Fig. 2a, b. The power spectral density (PSD) has been calculated as the Fourier transform (using the Discrete Fourier Transform (DFT)) of the autocorrelation function of the signal. In the calculation of the PSD we concatenated together the drifters trajectories of the Adriatic Sea and then we divided the time series into 70 portions, $1,000 \mathrm{~h}$ long, computing the spectra for each portion and averaging 
over the total number of pieces. The same procedure has been followed with the Ligurian sea trajectories, dividing the time series into 25 portions, $1,000 \mathrm{~h}$ long.

In the case of the Adriatic Sea, the PSD will concentrate on tidal frequencies since the daily motion in this shelf area is dominated by this periodic motion. In fact, the tidal components in Fig. 2a appear as peaks at about $0.04 \mathrm{~h}^{-1}$ (period of $24 \mathrm{~h}$ ) and $0.08 \mathrm{~h}^{-1}$ (period of $12 \mathrm{~h}$ ). Moreover, the inertial oscillations (period of nearly $18 \mathrm{~h}$ at the latitudes of the Ligurian and Adriatic seas, corresponding to a frequency of $0.05 \mathrm{~h}^{-1}$ ) are clearly visible. For the Ligurian Sea (Fig. 2b), the most evident peak is due to the inertial oscillations. In the open sea, the tidal components peaks should not appear and, in fact, the semi-diurnal tides peak does not appear at all, while the diurnal tides peak is less marked. The presence of the diurnal tides peak is due to the drifters that arrived near the coast.

It is apparent that there is no clear spectral gap for the longer periods that are of interest in this paper (daily to weekly time scales). The absence of an energy gap confirms the difficulty in choosing the averaging time interval for the calculation of the mean velocity.

\subsection{Estimates of the Lagrangian properties using Method 1} and Method 2

The Lagrangian properties have been first estimated using Method 1. In the Ligurian Sea, the diffusivities values are $K_{/ /}=2.7 \times 10^{7} \mathrm{~cm}^{2} / \mathrm{s}$ and $K_{\perp}=6.6 \times 10^{6} \mathrm{~cm}^{2} / \mathrm{s}$. The integral time scales are equal to $T_{/ /}=17.8 \mathrm{~h}$ and $T_{\perp}=6.3 \mathrm{~h}$. Lower diffusivity values have been obtained for the Adriatic Sea, $K_{/ /}=1.6 \times 10^{7} \mathrm{~cm}^{2} / \mathrm{s}$ and $K_{\perp}=3.1 \times 10^{6} \mathrm{~cm}^{2} / \mathrm{s}$, while the integral time scales $\left(T_{/ /}=17.8 \mathrm{~h}\right.$ and $\left.T_{\perp}=5.6 \mathrm{~h}\right)$ are similar to those estimated in the Ligurian Sea.

If we compare the computed values of the diffusivity coefficients with the one used in the Eulerian general circulation models, we find that these values are comparable to low-resolution general circulation models at $0.25^{\circ}$ horizontal resolution for the Mediterranean Sea (Pinardi et al. 1997). The present day models (Tonani et al. 2008) instead use values that are at least one order of magnitude smaller. Thus, the Lagrangian diffusivities computed from drifters in this way seem to be larger than the sub-grid scale values used in Eulerian numerical models.

Since the decorrelation time scale of the entire drifter track, discussed above, is lower than 7 days, any two locations of the same drifter separated in time by more than 7 days can be considered to be independent and positions more than 7 days apart can be set to be the origins of independent tracks (Method 2). The eddy diffusivities can be calculated using Eq. 3 or the time rate of change of the displacement variance (Eq. 4). From Eq. 3, the diffusivity values are $K_{/ /}=1.4 \times 10^{7} \mathrm{~cm}^{2} / \mathrm{s}$ and $K_{\perp}=3.1 \times 10^{6} \mathrm{~cm}^{2} / \mathrm{s}$. These values are slightly lower than the one obtained using a

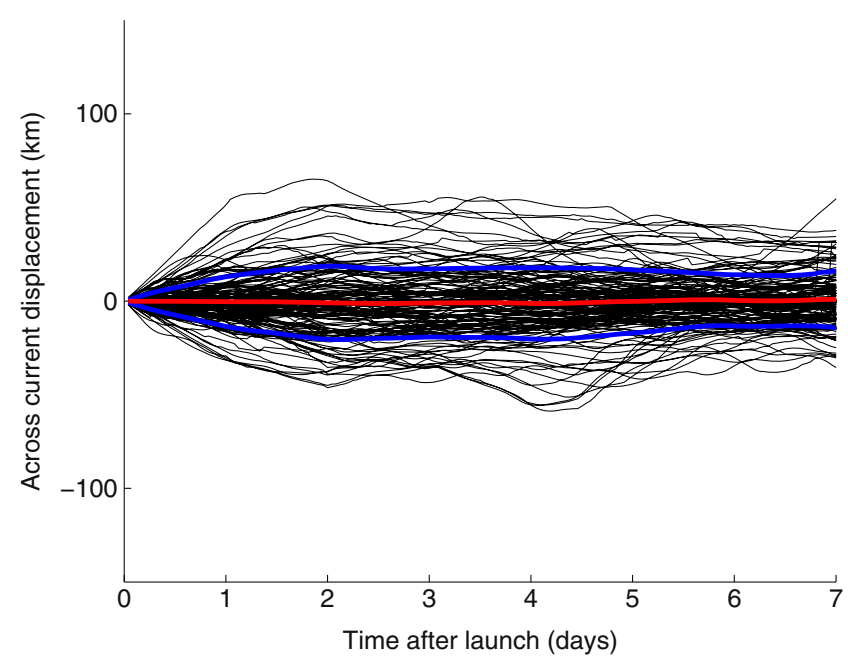

b

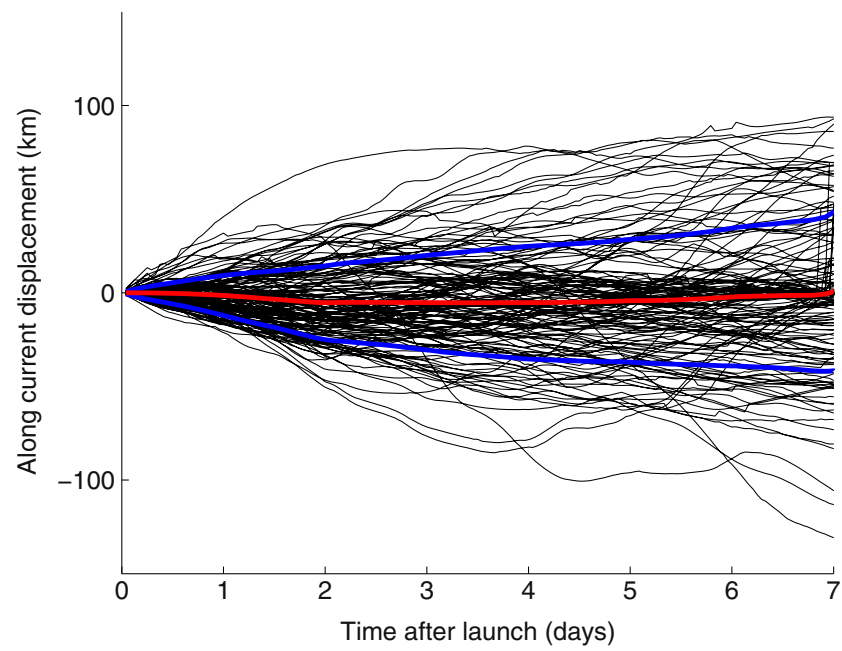

Fig. 3 Displacement components in streamwise coordinates versus time after deployment for the segmented drifter tracks (black lines). Time series of the mean displacements (red line) plus and minus one standard deviation (blue lines). a Across-stream component; $\mathbf{b}$ along-stream component

the individual tracks but still higher than the one used in general circulation models. The average integral time scale is about $T_{/ /}=10 \mathrm{~h}$ and $T_{\perp}=3.5 \mathrm{~h}$.

The evolution in time of the displacement of each drifter from the release point was calculated and the results are shown in Fig. 3a, b. Mean and standard deviation displacements are depicted versus time and superimposed over the displacements series. The picture looks like a diffusing plume of dye emitted from a continuous point source. Then, the standard deviation and the variance of the displacement were calculated and compared with Taylor's theoretical values (Fig. 5).

Figure 4 shows the two different dispersion regimes, the initial within $24 \mathrm{~h}$ and the successive one, as described in Eq. A.5 and Eq. A.6. Displacement standard deviations are 
a

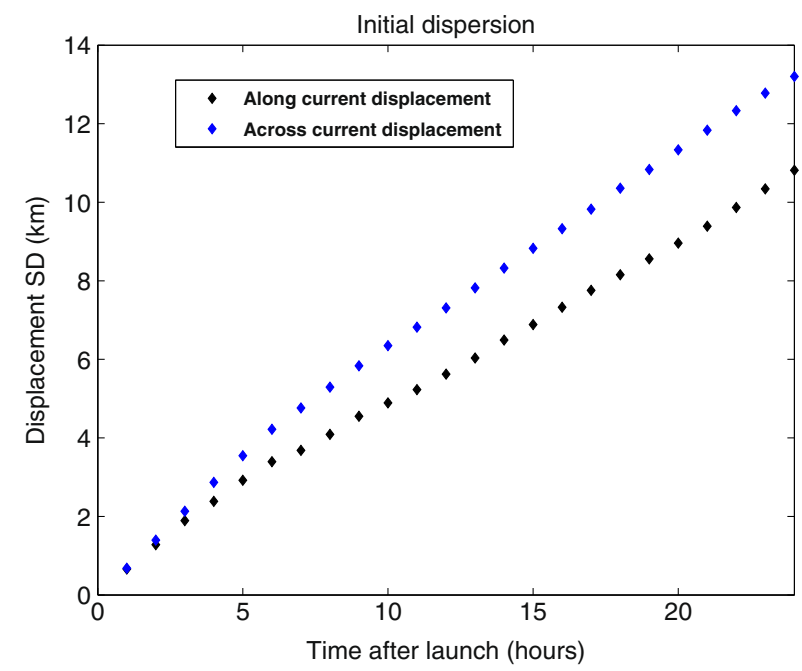

b

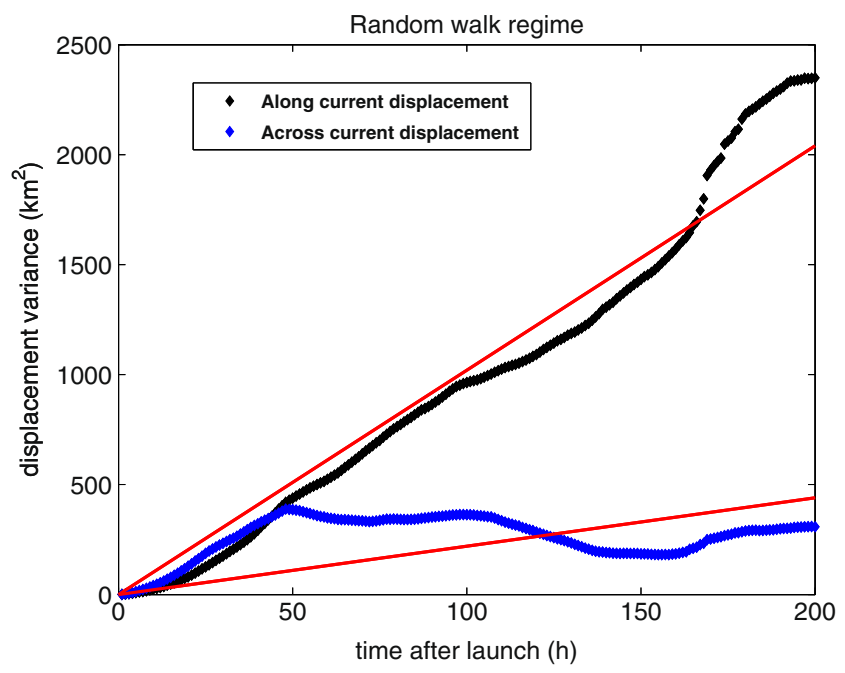

Fig. 4 a Standard deviation displacement component values versus time for the first $20 \mathrm{~h}$; b displacement component variance versus time for $200 \mathrm{~h}$. Taylor's theory predicts the variance dispersion depicted by the red lines

plotted in Fig. 4a. For the initial dispersion range there, is a linear evolution in time of the displacement standard deviation (Fig. 4a) so that Eq. A.5, expressed as $\left\langle d_{i}^{\prime 2}\right\rangle^{1 / 2}=\sqrt{2\left\langle u_{i}^{\prime 2}\right\rangle}$, is verified. The variances of the residual displacement are plotted in Fig. 4b. The two red lines correspond to the integration of Taylor's formula. For the along-current component, the observed dispersions are well modelled by the Taylor's theorem. Eq. A.6 can be rewritten as $\left\langle d_{i}^{\prime 2}\right\rangle=2 K_{i} t$ and in fact the slope of the curve equals the double of the diffusivity components $\left(K_{/ /}=1.4 \times 10^{7} \mathrm{~cm}^{2} / \mathrm{s}\right)$ obtained using Eq. 3 (Table 1).

4.3 Estimates of the Lagrangian properties using Method 3 (regime separations)

In this section, the computations will be carried out using an averaging time period $T$ equal to 7, 4 and 1 day, corresponding to non-overlapping segments of drifters tracks, whose origins are taken every successive 7, 4 and 1 day, respectively.

In Fig. 5, the Ligurian Sea and the Adriatic Sea 4-daylength segments are mapped subdivided into the four homogeneous classes As expected, trajectories having different values of the parameter $y$ are characterized by different shapes. The same behaviour has been found with the 7day-length segments (not shown).

In Fig. 5a, we can see that drifters belonging to Class I and II are mainly those trapped in the Liguro-ProvençalCatalan Current, which flows along the Italian (west of Genoa), French and Spanish coasts (Millot 1991). We found more Class I and II drifters located in the two northward flowing currents: the Eastern Corsican Current (ECC), which brings Tyrrhenian water into the Ligurian Sea and the Western Corsican Current, which is part of the large cyclonic circulation (Millot 1991). The looping trajectories, belonging to Classes III and IV are those experiencing looping behaviour. They are located mainly at the confluence between the ECC and Liguro-Provençal-Catalan Current along the Italian coast (Tuscany coast). Few looping trajectories are present in the open sea (few data are available in the open sea region).

In Fig. 5b, we can see that the drifters which do not experience looping behaviour are those trapped in the Western Adriatic Current, which belong to Classes I and II. The looping trajectories, belonging to Classes III and IV, are mainly concentrated in the Northern Adriatic and in the Central part of the Adriatic Sea, where the Middle Adriatic gyre is located (Artegiani et al. 1997). It is worth noting that most of the Class IV trajectories might be associated with inertial motions.

In Fig. 6, the Ligurian Sea and the Adriatic Sea 1-daylength segments are shown: Classes III and IV are the most populated, while there are only a few drifters belonging to Classes I and II.
Table 1 Summary of diffusivity and integral time scale values calculated using Methods 1 and 2

\begin{tabular}{lcccccc}
\hline Region & Method & Averaging period & $K_{/ /}\left[\mathrm{cm}^{2} / \mathrm{s}\right]$ & $K_{\perp}\left[\mathrm{cm}^{2} / \mathrm{s}\right]$ & $K_{/ /}[\mathrm{h}]$ & $K_{\perp}[\mathrm{h}]$ \\
\hline Ligurian Sea & 1 & 7 days-4 months & $2.7 \times 10^{7}$ & $6.6 \times 10^{6}$ & 17.0 & 6.3 \\
Adriatic Sea & 1 & 7 days-4 months & $1.6 \times 10^{7}$ & $3.1 \times 10^{6}$ & 17.8 & 5.6 \\
Ligurian Sea & 2 & 7 days-4 months & $1.4 \times 10^{7}$ & $3.1 \times 10^{6}$ & 10.0 & 3.5 \\
\hline
\end{tabular}


Fig. 5 Position diagram of the 4 days length trajectory data: a Ligurian Sea; b Adriatic Sea, divided into homogeneous classes using Rupolo's (2007) method: Class I $(y<0.2)$ : blue lines; Class II $(0.4<y<0.8)$ : black lines; Class III $(|y|=1, x<$ 1): green lines; Class IV $(|y|=1$, $x>1)$ : red lines a

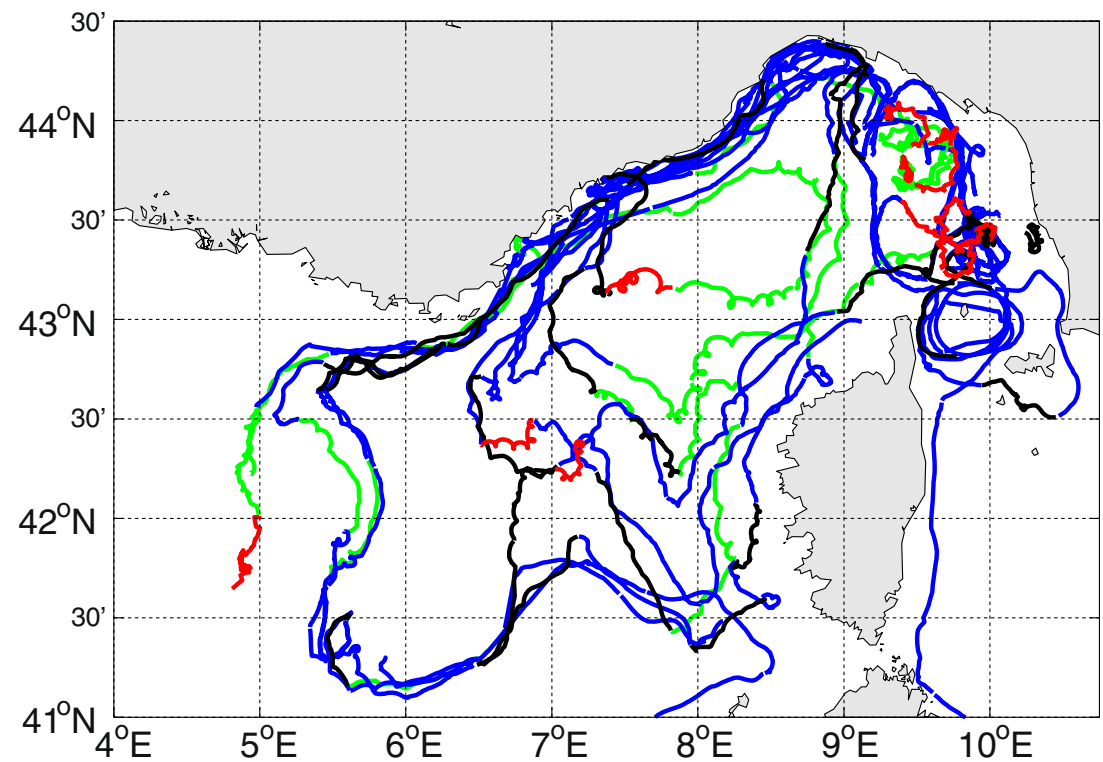

b

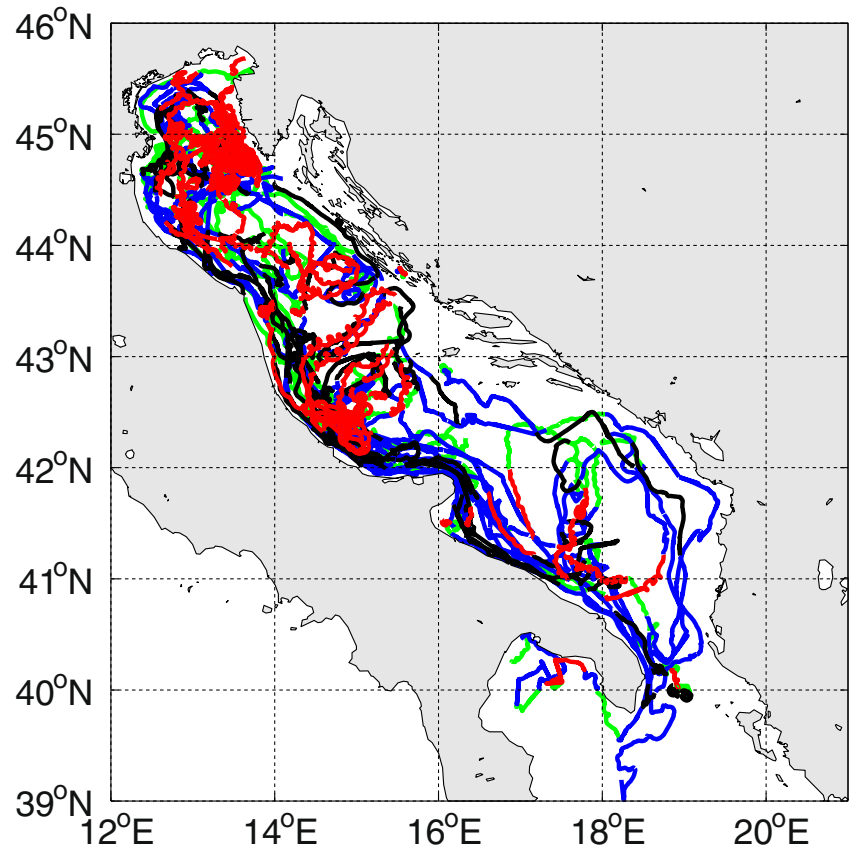

At least for the 4- and 7-day trajectories, the regime separations used in Method 3 showed the capability to separate the whole datasets in homogeneous classes: drifters of the same class, but that belong to different basins, display similar drifters shapes, diffusivity and correlation time scale values. Although the Rupolo (2007) classification presents some limitations since it seems to work only with averaging time periods higher than 1 day.
The mean Lagrangian autocorrelation for each class is shown in Fig. 7. The 4 days segments (Fig. 7a Ligurian Sea and Fig 7b Adriatic Sea) autocorrelation present an exponential shape for the drifters belonging to Classes I and II, while the autocorrelation for Classes III and IV presents an oscillatory character.

For the Ligurian Sea drifters (Fig. 7a), the oscillations are mainly attributable to the inertial oscillations (the oscillation period is $18 \mathrm{~h}$ ), while for the Adriatic Sea drifters the 
Fig. 6 Position diagram of the 1 day length trajectory data: a Ligurian Sea; b Adriatic Sea, divided into homogeneous classes using Rupolo's (2007) method: Class I $(y<0.2)$ : blue lines; Class II $(0.4<y<0.8)$ : black lines; Class III $(|y|=1, x<$ 1): green lines; Class IV $(|y|=1$, $x>1)$ : red lines a



b

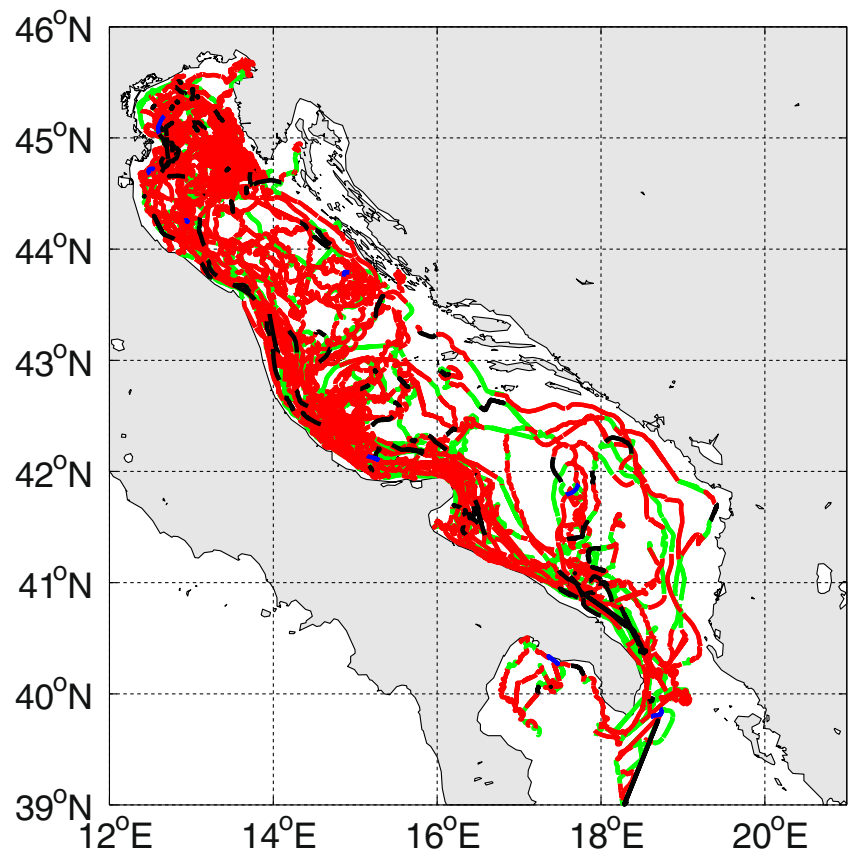

autocorrelation is affected also by the diurnal and semidiurnal tides (12- and 24-h periods). This behaviour can lead to an underestimation of the integral time scales and diffusivity for the drifters belonging to Classes III and IV.

The mean Lagrangian autocorrelations for the 1-day-length segments (Fig. 7c, d) present an exponential shape, which allow a correct calculation of the integral time scale and diffusivity.

For each averaging period, in Tables 2, 3 and 4, the average values for each homogeneous class of the diffusivity and integral time scale components are summarized.
Using an averaging time period of 7 and 4 days the results are quite similar (Tables 2 and 3). For the averaging time period equal to 7 days, a pronounced anisotropy of both eddy diffusivity and Lagrangian time scale occurs. Furthermore, using an averaging time period of 7 and 4 days, both eddy diffusivity and Lagrangian time scale decrease going from Classes I to IV. This is in agreement with Rupolo's (2007) findings. In particular, decreasing the averaging time period, we can notice that the average diffusivity values for Classes I and II decrease, while for 
Fig. 7 Lagrangian

autocorrelation function versus time lag: a Ligurian Sea 4 days length trajectories; b Adriatic 4 days length trajectories; c Ligurian Sea 1 day trajectory and $\mathbf{d}$ Adriatic Sea 1 day. The trajectories were subdivided into homogeneous classes using Rupolo's (2007) method: Class I $(y<0.2)$ : blue dots; Class II $(0.4<y<0.8)$ : black dots; Class III $(|y|=1, x<1)$ : green dots; Class IV $(|y|=1, x>1)$ : red dots a

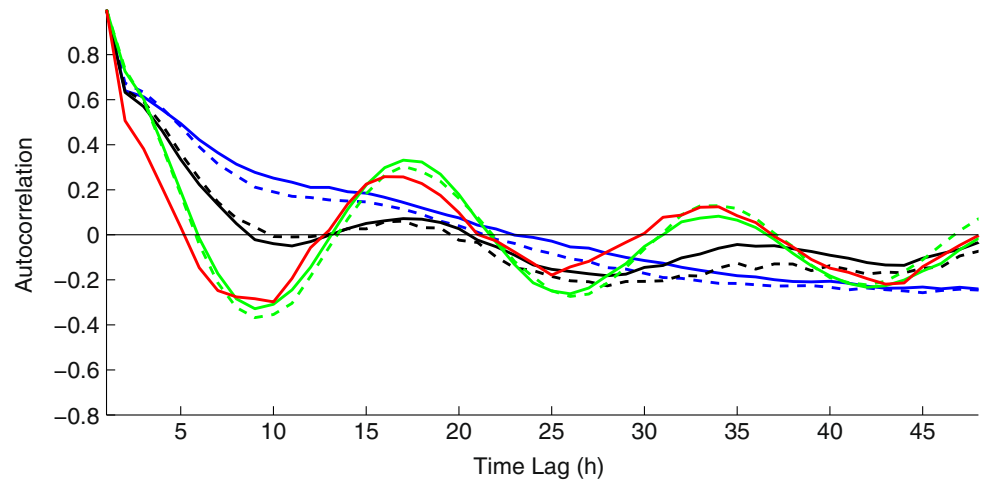

b

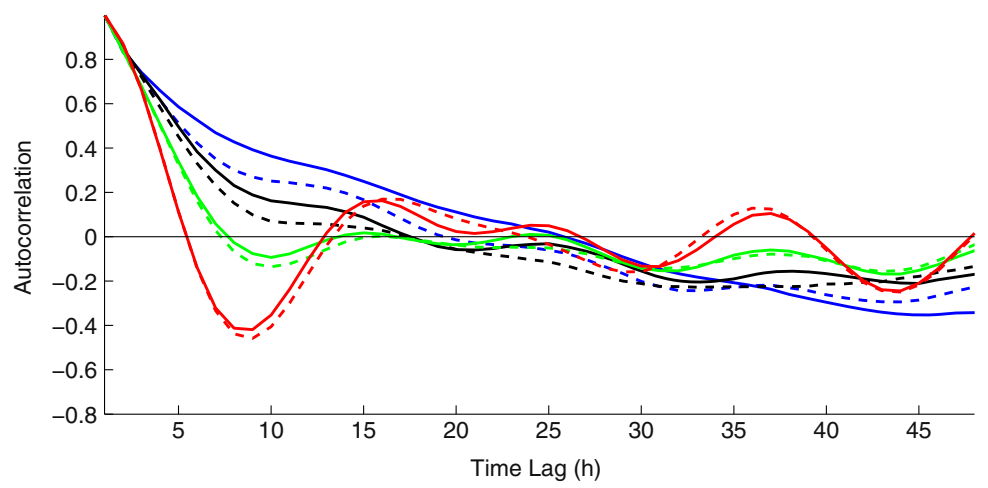

C

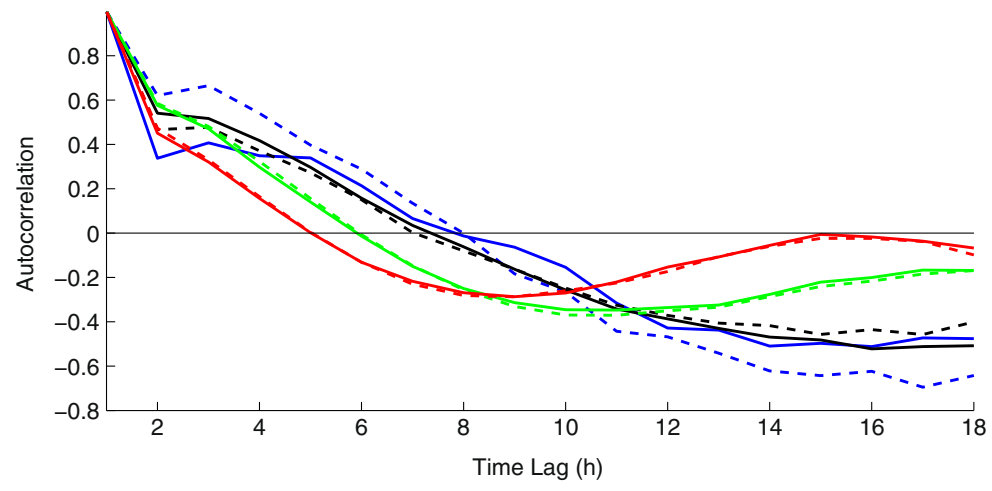

d

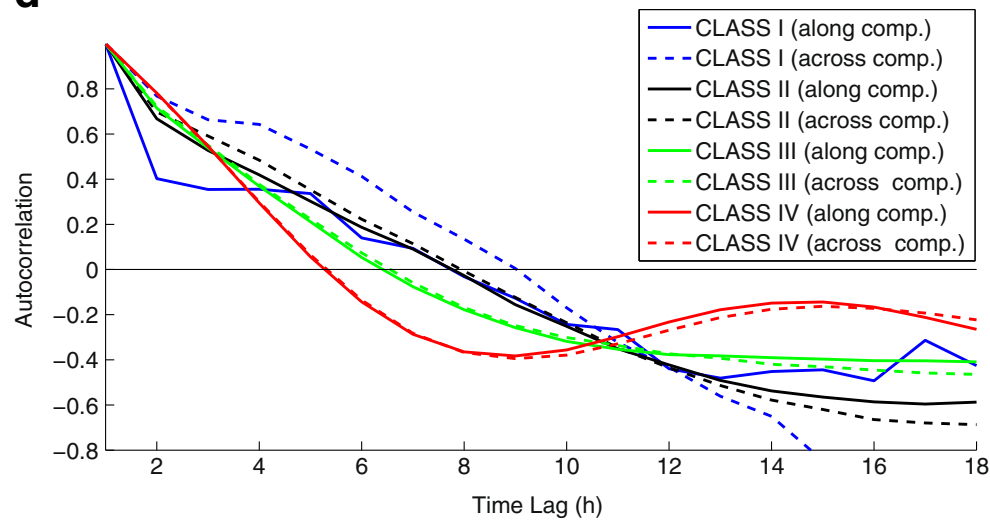


Table 2 Summary of diffusivity and integral time scale obtained using an averaging time period of 7 days, for Class I $(y<0.2)$, Class II $(0.4<y<$ $0.8)$, Class III $(|y|=1, x<1)$ and Class IV $(|y|=1, x>1)$

\begin{tabular}{|c|c|c|c|c|c|c|c|c|}
\hline \multirow[b]{2}{*}{ Region } & \multicolumn{2}{|c|}{$K_{/ /}\left[10^{6} \mathrm{~cm}^{2} / \mathrm{s}\right]$} & \multicolumn{2}{|c|}{$K_{\perp}\left[10^{6} \mathrm{~cm}^{2} / \mathrm{s}\right]$} & \multicolumn{2}{|l|}{$T_{/ /}[\mathrm{h}]$} & \multicolumn{2}{|l|}{$T_{\perp}[\mathrm{h}]$} \\
\hline & Adriatic Sea & Ligurian Sea & Adriatic Sea & Ligurian Sea & Adriatic Sea & Ligurian Sea & Adriatic Sea & Ligurian Sea \\
\hline Class I & 9.6 & 14.0 & 3.2 & 5.2 & 11.3 & 10.6 & 6.8 & 5.7 \\
\hline Class II & 4.2 & 3.7 & 2.0 & 2.1 & 5.9 & 4.0 & 4.4 & 2.8 \\
\hline Class III & 1.9 & 1.8 & 1.7 & 1.5 & 3.5 & 2.4 & 3.5 & 2.4 \\
\hline Class IV & 1.3 & 0.6 & 1.2 & 0.8 & 2.7 & 2.2 & 2.6 & 2.1 \\
\hline
\end{tabular}

Classes III and IV remain nearly constant in the range of $K_{/ /}=0.8-1.9 \times 10^{6} \mathrm{~cm}^{2} / \mathrm{s}$ and $K_{\perp}=0.7-1.7 \times 10^{6} \mathrm{~cm}^{2} / \mathrm{s}$ (considering both Adriatic and Ligurian Basin). Analogously, the correlation time scale averages are lower decreasing the averaging time period for the Classes I and II, but are nearly constant for the Classes III and IV between 2.3 and $3.5 \mathrm{~h}$ for both the along- and across-current components, which can be attributable to the inertial oscillations and tides that affect the autocorrelation function for Classes III and IV (Fig. 7a, b).

A relation between Eulerian currents and drifter-derived Lagrangian turbulence will be examined. The first idea is to investigate if the total diffusivity, computed from the diffusivity components as $K=(1 / 2)\left(K_{/ /}+K_{\perp}\right)$, can be parameterized simply in terms of the Eddy Kinetic Energy (EKE) of the Lagrangian fluctuations, i.e.:

$\mathrm{EKE}=\sigma_{\mathrm{U}}^{2}=\frac{1}{2}\left\langle\mathrm{u}^{\prime 2}+\mathrm{v}^{\prime 2}\right\rangle$

The relationship between EKE and $K$, calculated using 4 days long trajectories, is reported in Fig. 8. The results are plotted for the four different classes (considering together both the Adriatic and Ligurian Sea data). It is clear the presence of a linear relationship between EKE and $\mathrm{K}$, where the line slopes are $8.4 \mathrm{~h}$ (Class I), $4.7 \mathrm{~h}$ (Class II), $3.5 \mathrm{~h}$ (Class III) and $2.4 \mathrm{~h}$ (Class IV). Those values are in agreement with the integral time scales found for each class (see Table 3). This linear behaviour is in agreement with what was found by Rupolo (2007) in the same $\sigma_{U}$ range of variation considered here. The integral time scale increases as the class of trajectories decreases. In particular, for Class IV is observed a low data dispersion, probably due to the strong influence of inertial motions that frequently fall in this class

The parameters calculated using 1 day (Table 4) shows the turbulence as almost isotropic. As already pointed out, the Rupolo (2007) classification seems no to work with averaging time period lower than 1 day, leading to an homogeneity of the time scale and diffusivity components. The eddy diffusivity values found using 1 day drifters segments for Classes III and IV represent the diffusivity due to the turbulent, Lagrangian coherent structures and sub-grid scale processes not completely resolved by the OGCMs.

Eddy diffusivity value calculated averaging over 7, 4 and 1 day can be used with OGCM current fields with a horizontal resolution approximately equal to $60-120,35-70$ and $9-17 \mathrm{~km}$, respectively. To estimate the correct value for higher resolution OGCMs, we should perform the mean flow calculation over hourly time periods but, given that the drifter sampling frequency is only $1 \mathrm{~h}$, the statistics will not be enough to calculate mean displacements and fluctuations. The values obtained using an averaging period of 1 day are now in the order of magnitude of the diffusivity coefficients used by current state of the art OGCMs (Tonani et al. 2008; Oddo et al. 2009).

\section{Estimates of Lagrangian properties from simulated trajectories}

In this section, horizontal diffusivities and integral time scales computed from the observed drifters will be compared with the same quantities calculated from simulated trajectories. The purpose of this section is to perform a

Table 3 As in Table 2, but for an averaging time period of 4 days

\begin{tabular}{|c|c|c|c|c|c|c|c|c|}
\hline \multirow[b]{2}{*}{ Region } & \multicolumn{2}{|c|}{$K_{/ /}\left[10^{6} \mathrm{~cm}^{2} / \mathrm{s}\right]$} & \multicolumn{2}{|c|}{$K_{\perp}\left[10^{6} \mathrm{~cm}^{2} / \mathrm{s}\right]$} & \multicolumn{2}{|l|}{$T_{/ /}[\mathrm{h}]$} & \multicolumn{2}{|l|}{$T_{\perp}[\mathrm{h}]$} \\
\hline & Adriatic Sea & Ligurian Sea & Adriatic Sea & Ligurian Sea & Adriatic Sea & Ligurian Sea & Adriatic Sea & Ligurian Sea \\
\hline Class I & 6.1 & 6.4 & 3.1 & 5.1 & 8.8 & 6.7 & 6.9 & 6.1 \\
\hline Class II & 4.6 & 2.7 & 2.3 & 2.5 & 6.0 & 3.2 & 4.9 & 3.5 \\
\hline Class III & 1.7 & 1.6 & 1.3 & 1.5 & 3.5 & 2.5 & 3.4 & 2.5 \\
\hline Class IV & 1.2 & 0.9 & 1.2 & 1.1 & 2.5 & 1.6 & 2.6 & 1.8 \\
\hline
\end{tabular}


Table 4 As in Table 2, but for an averaging time period of 1 day

\begin{tabular}{|c|c|c|c|c|c|c|c|c|}
\hline \multirow[b]{2}{*}{ Region } & \multicolumn{2}{|c|}{$K_{/ /}\left[10^{6} \mathrm{~cm}^{2} / \mathrm{s}\right]$} & \multicolumn{2}{|c|}{$K_{\perp}\left[10^{6} \mathrm{~cm}^{2} / \mathrm{s}\right]$} & \multicolumn{2}{|l|}{$T_{/ /}[\mathrm{h}]$} & \multicolumn{2}{|l|}{$T_{\perp}[\mathrm{h}]$} \\
\hline & Adriatic Sea & Ligurian Sea & Adriatic Sea & Ligurian Sea & Adriatic Sea & Ligurian Sea & Adriatic Sea & Ligurian Sea \\
\hline Class I & 0.8 & 1.7 & 0.9 & 2.9 & 2.3 & 2.3 & 3.9 & 3.2 \\
\hline Class II & 1.3 & 1.3 & 0.9 & 1.1 & 2.9 & 2.6 & 3.1 & 2.4 \\
\hline Class III & 0.8 & 1.0 & 0.7 & 1.0 & 2.6 & 2.1 & 2.6 & 2.2 \\
\hline Class IV & 1.0 & 0.9 & 0.8 & 0.8 & 2.4 & 1.5 & 2.3 & 1.6 \\
\hline
\end{tabular}

validation of the OGCM's Lagrangian properties such as the horizontal diffusivity. The drifters were simulated using a trajectory model forced by different OGCM current fields. The focus will be on how the Lagrangian properties depend on the temporal resolution of the input velocity fields.

Every day simulated drifters were "deployed" at the actual drifters locations (with a simulation length of 1 day), in order to reproduce the 1-day-long non-overlapping segments presented in Section 2 (Method 3).

As for observations, Lagrangian integral time scale components have been calculated as the integral of the velocity autocorrelation up to the first zero-crossing (Eq. A.2) and Lagrangian diffusivity components have been computed using Eq. 3.

The trajectory model algorithm (Fabbroni 2009) integrates Eq. 2 assuming the drifters as transported only by the horizontal currents components and the turbulent displacement represented by a random walk model:

$\mathrm{d} \mathbf{x}(t)=\left(\begin{array}{c}U(\mathbf{x}, t) \\ V(\mathbf{x}, t)\end{array}\right) \mathrm{d} t$

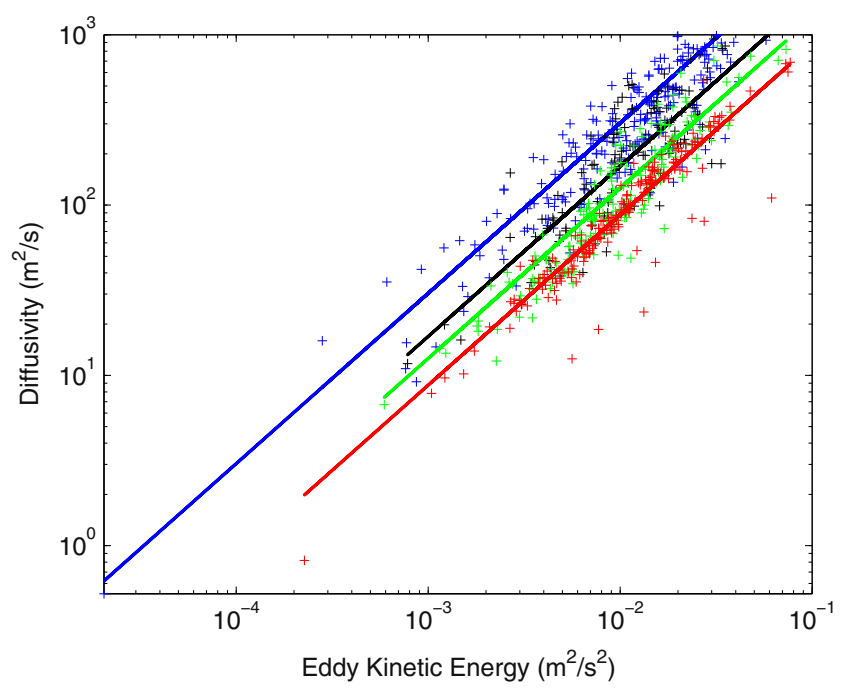

Fig. 8 Relation between EKE and the horizontal diffusivity calculated using 4 days trajectories of Adriatic Sea and Ligurian Sea datasets (Class I $(y<0.2)$ : blue dots; Class II $(0.4<y<0.8)$ : black dots; Class III $(|y|=1, x<1)$ : green dots; class IV $(|y|=1, x>1)$ : red dots $)$. Linear regressions for each class of data show slopes of $8.4 \mathrm{~h}$ (Class I), $4.7 \mathrm{~h}$ (Class II), $3.5 \mathrm{~h}$ (Class III) and $2.4 \mathrm{~h}$ (Class IV) where $\mathbf{x}$ is the particle position, $\mathrm{U}(\mathbf{x}, \mathrm{t}), \mathrm{V}(\mathbf{x}, \mathrm{t})$ are the zonal and meridional components of the currents velocity provided by the OGCM at the particle position.

The trajectories are calculated off-line, i.e. with the stored velocity fields from the OGCMs. The horizontal velocity values at the particle position are computed applying a bilinear interpolation to the velocities surrounding the particle position, $\mathbf{x}$. At each time step, a linear interpolation in time of the horizontal currents provided by the external Eulerian model is computed.

The drifters trajectories were simulated considering only the advection due the Eulerian currents, in order to evaluate the gap between the horizontal diffusivities coming from the simulated trajectories with the one coming from the real ones. That gap, due to missing physics and sub-grid processes not solved by the OGCM, can be filled using different parameterization for the turbulent displacement.

In order to study the effect of the velocity fields temporal resolution, a subset of the Ligurian Sea drifters ( 777 drifters segments, deployed between May 2007 and September 2007) were simulated using the daily mean and hourly mean currents provided by the MFS (Pinardi et al. 2003); (Pinardi and Coppini 2010) with and horizontal resolution of $1 / 16^{\circ}$ $(6.5 \mathrm{~km})$.

The MFS system is composed of an OGCM (Tonani et al. 2008) at $6.5 \mathrm{~km}$ horizontal resolution and 72 vertical levels and an assimilation scheme (Dobricic and Pinardi 2008) which corrects the model's initial guess with all the available in situ and satellite observations producing analyses. In this work, we will use the analyses as daily and hourly mean products.

Figure 9a shows the Ligurian Sea 1-day-long drifter segments simulated using the MFS daily analysis, while Fig. 9b the modelled drifters using the MFS hourly analysis.

Comparing with the observations (Fig. 9c), the model (daily or hourly mean) tends to underestimate current velocities, resulting in a smaller displacement of the simulated trajectories than the real ones. As already observed for the observation, the Rupolo (2007) classification does not work with averaging time period lower than 1 day, leading to a homogeneity of the time scale and diffusivity components, in fact the segments belong mainly to Classes III and IV. 
Fig. 9 Position diagram of the 1 day length simulated and real trajectories: a modelled trajectories using daily mean MFS currents and $\mathbf{b}$ hourly mean MFS currents and $\mathbf{c}$ real drifters trajectories deployed between May 2007 and

September 2007. The

trajectories were simulated without adding any turbulent displacement and considering only the advection due to the model. The modelled

trajectories are subdivided into homogeneous classes using Rupolo's (2007) method: Class I $(y<0.2)$ : blue lines, Class II $(0.4<y<0.8)$ : black lines; Class III $(|y|=1, x<1)$ : green lines;

Class IV $(|y|=1, x>1)$ : red lines a



b

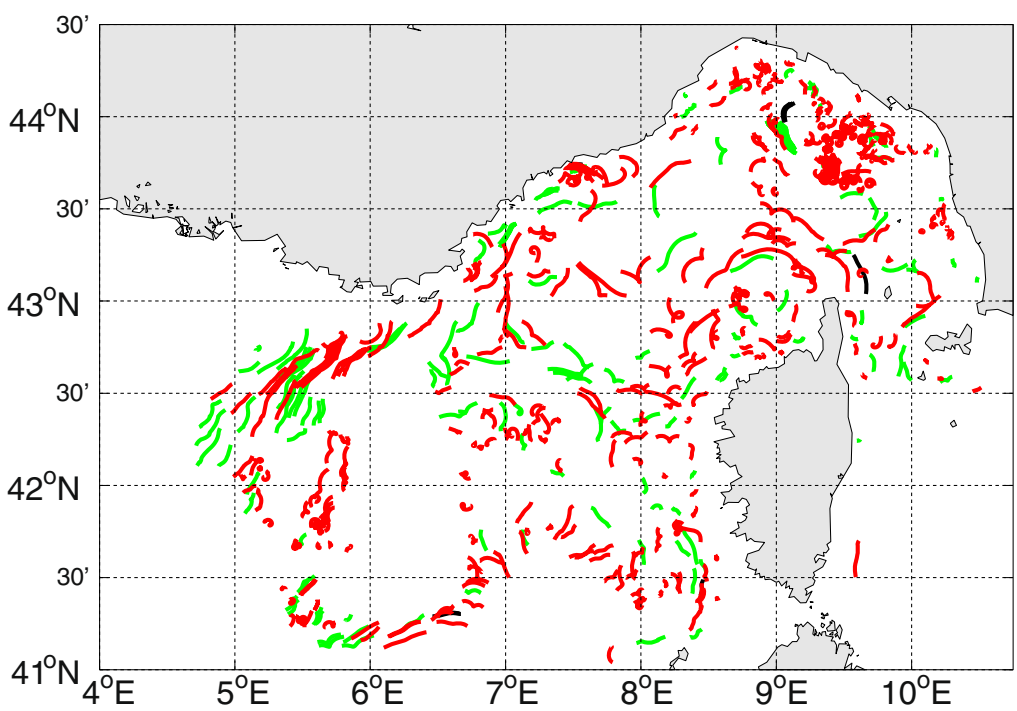

C

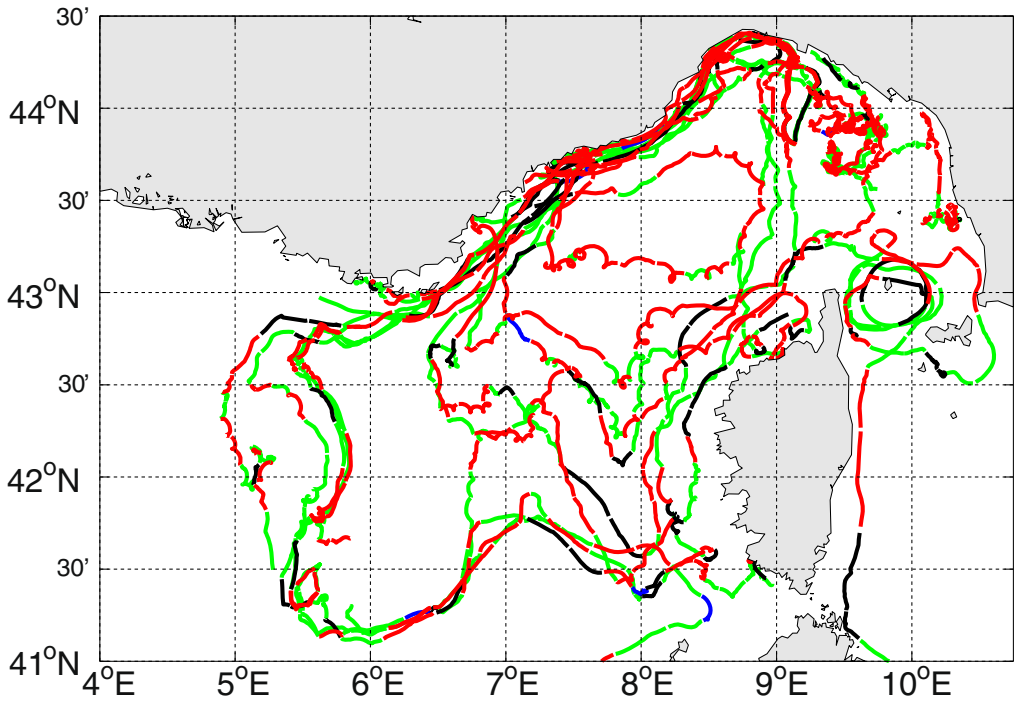


Using the daily mean currents as forcing (Fig. 9a), the looping behaviour is not recovered by the simulated trajectories, while the trajectories simulated using the hourly currents (Fig. 9b), present a looping behaviour due to the higher resolution of the forcing; however, the inertial oscillations are not always properly reproduced by the model.

In Table 5, diffusivities and integral time scales obtained from the simulated drifters using the daily and hourly MFS currents fields are compared with the values obtained with the real drifters (deployed between May 2007 and September 2007). Integral time scales from simulated drifters using both daily and hourly mean currents are in agreement with the values coming from the observations.

The modelled trajectories solutions include only the implicit large-scale diffusion due to the OGCMs turbulent parameterization in the momentum equations, since they are passively advected by the model currents without adding any turbulent displacement. Using the daily mean currents, horizontal diffusivity components are weaker than real values. The horizontal diffusivity obtained using hourly mean are still weaker then the real values, but higher than the values obtained using the daily mean currents.

In order to reduce the discrepancies between the modelled and observed trajectories, the turbulent displacement has to be added to the advection displacement. We argue that higher diffusivity or a higher-order stochastic model in the Lagrangian trajectory equation would be needed when using daily mean currents than the one needed when hourly fields are used.

\section{Discussion and conclusions}

In this work, a method to calculate the diffusivity on the basis of the drifter datasets has been set up. Using surface drifters observations collected in the Liguro-Provençal basin and in the Adriatic Sea (Eastern Mediterranean Sea) the Lagrangian sub-grid scale diffusion has been computed in terms of $K_{i}$ and $T_{i}$. The results show that the diffusivity and the turbulent time scale take different values depending on the method used in the calculation of the mean flow velocity.

Using a mean flow averaging time period equal to the drifter trajectory length, we found diffusivity values ranging between $K_{/ /}=1.6-2.7 \times 10^{7} \mathrm{~cm}^{2} / \mathrm{s}$ for the along-current direction and between $K_{\perp}=3.1-6.6 \times 10^{6} \mathrm{~cm}^{2} / \mathrm{s}$ for the acrosscurrent direction. The average integral time scales are $T_{/ /}=$ $17 \mathrm{~h}$ and $T_{\perp}=6 \mathrm{~h}$. Results of the same order of magnitude have been found using Method 2.

Those values of the diffusivity are in agreement with the results obtained in the Adriatic Sea by Falco et al. (2000), Poulain (2001) and Ursella et al. (2006). They found values of $K_{i}$ in the range of $1-2 \times 10^{7} \mathrm{~cm}^{2} / \mathrm{s}$ in the along-basin direction. Similar values (diffusivities ranging in $1-5 \times 10^{7} \mathrm{~cm}^{2} / \mathrm{s}$ ) have been estimated in the central Mediterranean Sea by (Poulain and Zambianchi 2007). Note that in the above-mentioned works, the drifters data were sub-sampled every $6 \mathrm{~h}$ and the residual velocities were calculated by removing a mean velocity, calculated averaging the drifters velocities over long time periods. We believe this is an overestimation (one or two orders of magnitude) of the correct $K_{i}$ to be used in a dispersion model. A direct consequence of the overestimation of $K_{i}$ is that its direct use as input parameter in oil spill or particletracking models may lead to significant errors in water-quality calculations. The results of $T_{i}$ and $K_{i}$ that we found using a mean flow averaging time period equal to the drifter trajectory length refer to structures with spatial scales as large as $2,000 \mathrm{~km}$ (the drifter displacement corresponding to the maximum track length of 4 months will be about $2,000 \mathrm{~km}$ assuming a velocity of $0.2 \mathrm{~m} / \mathrm{s}$ ). These structures cannot be considered part of the sub-grid scale parameterization, because they are going to be resolved deterministically by the model. Thus, the diffusivity values found using Method 1 and 2 could not be used in Lagrangian models coupled with OGCMs which have higher resolution.

Using the regime separation method we found that, at least for the 4- and 7-day trajectories of the same class, but that belong to different basins, display similar drifters shapes,

Table 5 Summary of diffusivity and integral time scale obtained from the simulated drifters using the MFS daily mean currents and the MFS hourly mean currents

\begin{tabular}{|c|c|c|c|c|c|c|c|c|c|c|c|c|}
\hline & \multicolumn{3}{|c|}{$K_{/ /}\left[10^{6} \mathrm{~cm}^{2} / \mathrm{s}\right]$} & \multicolumn{3}{|c|}{$K_{\perp}\left[10^{6} \mathrm{~cm}^{2} / \mathrm{s}\right]$} & \multicolumn{3}{|l|}{$T_{/ /}[\mathrm{h}]$} & \multicolumn{3}{|l|}{$T_{\perp}[\mathrm{h}]$} \\
\hline & $\begin{array}{l}1 \text { day } \\
\text { segments } \\
\text { (May07- } \\
\text { Sept07) }\end{array}$ & $\begin{array}{l}\text { MFS } \\
24 \mathrm{~h}\end{array}$ & $\begin{array}{l}\text { MFS } \\
1 \mathrm{~h}\end{array}$ & $\begin{array}{l}1 \text { day } \\
\text { segments } \\
\text { (May07- } \\
\text { Sept07) }\end{array}$ & $\begin{array}{l}\text { MFS } \\
24 \mathrm{~h}\end{array}$ & $\begin{array}{l}\text { MFS } \\
1 \mathrm{~h}\end{array}$ & $\begin{array}{l}1 \text { day } \\
\text { segments } \\
\text { (May07- } \\
\text { Sept07) }\end{array}$ & $\begin{array}{l}\text { MFS } \\
24 \mathrm{~h}\end{array}$ & $\begin{array}{l}\text { MFS } \\
1 \mathrm{~h}\end{array}$ & $\begin{array}{l}1 \text { day } \\
\text { segments } \\
\text { (May07- } \\
\text { Sept07) }\end{array}$ & $\begin{array}{l}\text { MFS } \\
24 \mathrm{~h}\end{array}$ & $\begin{array}{l}\text { MFS } \\
1 \mathrm{~h}\end{array}$ \\
\hline Class II & 1.4 & 0.1 & 0.4 & 1.2 & 0.1 & 0.3 & 2.7 & 3.2 & 3.7 & 2.5 & 3.0 & 3.3 \\
\hline Class III & 1.0 & 0.2 & 0.4 & 1.0 & 0.2 & 0.4 & 2.2 & 2.7 & 2.6 & 2.3 & 2.7 & 2.7 \\
\hline Class IV & 1.0 & 0.2 & 0.7 & 1.0 & 0.3 & 0.7 & 1.9 & 2.0 & 2.7 & 1.9 & 2.2 & 2.8 \\
\hline
\end{tabular}

The simulated drifter were 4 days long, subdivided in classes as defined by Rupolo (2007): Class I $(y<0.2)$, Class II $(0.4<y<0.8)$, Class III $(|y|=1, x$ $<1)$ and Class IV $(|y|=1, x>1)$. The simulated segments belonging to Class I were not in a sufficient number to provide a statistics 
diffusivity and correlation time scale values. Although we found that the Rupolo (2007) classification presents some limitations since it works only with averaging time periods higher than 1 day.

In addition, we described the relation between the EKE and the diffusivity calculated using the 4 days drifters segments, both calculated from the drifters observations, and we found that a relation exists. The diffusivity increases with EKE, with a slope equal to the average integral time scale. Some other studies indicate that the diffusivity scales with EKE (Figueroa and Olson 1989; Poulain and Niiler 1989), which makes sense if $T_{i}$ is a constant time scale. If a constant- $T$ rule was universal, diffusivity could be estimated directly from distribution of EKE which would be an important result for practical applications. However this rule is not universal. In fact, subsequent studies showed that a constant- $T$ rule did not apply elsewhere and suggested that the diffusivity scales with the rms velocity (Krauss and Boning 1987; Brink et al. 1991; Zhang et al. 2001). Thus, in the future remains to determine what are the dynamical regimes that make the constant- $T$ rule regionally applicable.

Using an averaging time period equal to 7 and 4 days and a regime separations method (Rupolo 2007) we found that the mean Lagrangian autocorrelation for each class present an exponential shape for the drifters belonging to Classes I and II, while the autocorrelation for Classes III and IV presents an oscillatory character, which can be attributable to inertial oscillations and tides. This behaviour led to an underestimation of the integral time scales and diffusivity for the drifters belonging to Classes III and IV. In fact, we found that decreasing the averaging time period the average diffusivity values for Classes I and II (trajectories trapped in mesoscale structures) decrease, while for Classes III and IV (looping trajectory) remain nearly constant in the range of $K_{/ /}=0.8-1.9 \times 10^{6} \mathrm{~cm}^{2} / \mathrm{s}$ and $K_{\perp}=0.7-1.7 \times 10^{6} \mathrm{~cm}^{2} / \mathrm{s}$ (considering both Adriatic and Ligurian Basin). Analogously, the correlation time scale averages are lower decreasing the averaging time period for the Classes I and II, but are nearly constant for the Classes III and IV between 2.3 and $3.5 \mathrm{~h}$ for both the along- and across-current components. Instead, the mean Lagrangian autocorrelations for the 1 day drifters segments present an exponential shape, which allow a correct calculation of the integral time scale and diffusivity. Using an averaging time period equal to 1 day, the Rupolo (2007) regime separations method does not work, leading to an homogeneity of the time scale and diffusivity components: Classes III and IV are the most populated, while there are only a few drifters belonging to Classes I and II. The eddy diffusivity values found for Class III and IV represent the diffusivity due to the turbulent, Lagrangian coherent structures and subgridscale processes not completely resolved by the OGCMs. The values obtained using 1-day segments are now in the right order of magnitude of the diffusivity coefficients used by current state of the art ocean general circulation models in the Mediterranean Sea (Tonani et al. 2008; Oddo et al. 2009). Eddy diffusivity values calculated averaging over 7, 4 and 1 day can be used with OGCM current fields with a horizontal resolution approximately equal to $60-120,35-70$ and $9-17 \mathrm{~km}$, respectively.

Finally, horizontal diffusivity values have been obtained from simulated trajectories, using a trajectory model forced by daily and hourly mean currents provided by the MFS OGCM, with a horizontal resolution of $6.5 \mathrm{~km}$. The modelled trajectories solutions include only the implicit largescale diffusion due to the OGCM turbulent parameterization in the momentum equations, since they are passively advected by the model currents without adding any turbulent displacement. Thus, the discrepancies between the horizontal diffusivity and integral time scales calculated from the real drifters and the modelled trajectories allow us to evaluate the gap, due to missing physics and sub-grid processes not solved by the OGCM, to be filled with the turbulent displacement parameterization in the trajectory equation. The discrepancies between modelled and observed horizontal diffusivity are larger using daily mean than hourly mean currents. Thus, we argue that higher diffusivity or a higher-order stochastic model in the Lagrangian trajectory equation would be needed when using daily mean currents than the one needed when hourly fields are used.

In order to definitely solve the problem of the determination of the integral time scale and diffusivity in Lagrangian models coupled to Eulerian model flow fields, we should estimate the Lagrangian fluctuations with respect to a mean flow calculated over a hourly time period. Our data set does not allow this calculation, given that the drifter sampling frequency is just $1 \mathrm{~h}$. Thus, further research and higher drifter sampling frequency will be needed to finally establish the correct diffusivities for Lagrangian particle models.

Acknowledgements Michela De Dominicis and Nadia Pinardi were supported by the European Commission MyOcean Project (Grant Agreement 218812-1-FP7-SPACE 2007-1) and by the PRIMI project funded by ASI (Agenzia Spaziale Italiana).

Open Access This article is distributed under the terms of the Creative Commons Attribution License which permits any use, distribution, and reproduction in any medium, provided the original author(s) and the source are credited.

\section{Appendix A. Lagrangian Statistics}

The quasi-Lagrangian nature of the drifter tracks is exploited to obtain Lagrangian scales of variability and to describe diffusive transport by the eddy field. Let $u_{i}\left(x_{0}, \mathrm{y}_{0}, t\right)$ be the velocity at time $t$ of the drifter passing trough $\left(x_{0}, y_{0}\right)$ at the 
initial time $\mathrm{t}_{0}$. The Lagrangian autocorrelation function along a generic $i$-axis is defined as (Poulain and Niiler 1989):

$$
\begin{aligned}
R_{i}\left(\tau, T, t_{0}, x_{0}, y_{0}\right) & =\frac{\frac{1}{T} \int_{t_{0}}^{t_{0}+T} u_{i}{ }^{\prime}\left(x_{0}, y_{0}, t\right) u_{i}{ }^{\prime}\left(x_{0}, y_{0}, t+\tau\right) \mathrm{d} t}{\frac{1}{T} \int_{t_{0}}^{t_{0}+T} u_{i}{ }^{\prime}\left(x_{0}, y_{0}, t\right) u_{i}{ }^{\prime}\left(x_{0}, y_{0}, t\right) \mathrm{d} t} \\
& =\frac{\left\langle u_{i}{ }^{\prime}\left(x_{0}, y_{0}, t\right) u_{i}{ }^{\prime}\left(x_{0}, y_{0}, t+\tau\right)\right\rangle_{\mathrm{L}}}{\left\langle u_{i}{ }^{\prime}\left(x_{0}, y_{0}, t\right)^{2}\right\rangle_{\mathrm{L}}}
\end{aligned}
$$

where $T$ is the time interval over which the Lagrangian average $\left\langle>_{\mathrm{L}}\right.$ is calculated and $u_{i}{ }^{\prime}=u_{i}-\overline{u_{i}}=u_{i}-\left\langle u_{i}\right\rangle_{\mathrm{L}}$ is a residual velocity, obtained by subtracting the mean velocity for each drifter.

For homogeneous and stationary fields, the dependence of the average on $T, x_{0}, y_{0}$ and $t_{0}$ vanishes. There is a large variability in the individual autocorrelation functions. Most of these have significant negative lobes and approach a zero value at small time lag. The Lagrangian integral time scale is the time over which a drifter "remembers" its velocity. It is defined by:

$T_{i}^{\mathrm{L}}=\int_{0}^{\mathrm{t}} R_{i}(\tau) \mathrm{d} \tau$

The integral of the autocorrelation which appears in definitions (A.2) is generally time dependent and does not approach a constant limit as $\mathrm{t}$ increases. The integral time scale can be calculated as the integral of the velocity autocorrelation until the first zero-crossing. This corresponds to the first maximum of the integral scales and the values can be considered as upper bound to the true scales.

The probability density of particle displacements $p\left(x_{i}, t ; x_{i 0}\right.$, $t_{0}$ ) plays a major role in the transport of the mean concentration of a passive scalar property (Davis 1983). Its second moment is the displacement covariance and is defined as:

$\left\langle d_{i}^{\prime 2}\right\rangle(t)=\int_{A} p\left(x_{i}, t ; x_{i 0}, t_{0}\right) d_{i}^{\prime} d_{i}^{\prime}\left(d x_{i 0}\right)^{3}$

where $d_{i}^{\prime}=x_{i}-x_{i 0}-\left\langle u_{i}\right\rangle\left(t-t_{0}\right)$ is a residual displacement, $p\left(x_{i}, t ; x_{i 0}, t_{0}\right)$ is the probability that a particle released at $\left(x_{i 0}, t_{0}\right)$ reaches $\left(x_{i}, t\right)$ and $A$ is the domain of all the possible initial conditions. For homogeneous and stationary fields, a simple formula relates the single-particle diffusivity $\left(K_{i}\right)$, defined as the time rate of change of the displacement covariance, to the integral of the Lagrangian autocorrelation. This relation, first derived by Taylor (1921), is expressed as:

$K_{i}(t)=\frac{1}{2} \frac{\mathrm{d}}{\mathrm{d} t}\left\langle d_{i}^{\prime 2}\right\rangle=\left\langle u_{\mathrm{i}}^{\prime 2}\right\rangle \int_{0}^{t} R_{i}(\tau) \mathrm{d} \tau=\left\langle u_{i}^{\prime 2}\right\rangle T_{i}^{\mathrm{L}}$

Eq. A.4 approaches two independent limits, viz.:

- Initial dispersion:

$$
\text { If } t<<T_{i}^{\mathrm{L}}, \text { then } \frac{1}{2} \frac{\mathrm{d}}{\mathrm{d} t}\left\langle d_{i}^{\prime 2}\right\rangle=\left\langle u_{i}^{\prime 2}\right\rangle t
$$

- Random walk regime:

$$
\text { If } t>>T_{i}^{\mathrm{L}}, \text { then } \frac{1}{2} \frac{\mathrm{d}}{\mathrm{d} t}\left\langle d_{i}^{\prime 2}\right\rangle=\left\langle u_{i}^{\prime 2}\right\rangle T_{i}^{\mathrm{L}}
$$

\section{References}

Artegiani A, Paschini E, Russo A, Bregant D, Raicich F, Pinardi N (1997) The Adriatic Sea general circulation. Part II: baroclinic circulation structure. J Phys Oceanogr 27(8):1515-1532

Bauer S, Swenson M, Griffa A, Mariano M, Owens K (2002) Eddy mean flow decomposition and eddy diffusivity estimates in the tropical Pacific Ocean: 2. Results. J Geophys Res 107:3154. doi:10.1029/2000JC000613

Berloff PS, McWilliams JC (2003) Material transport in oceanic gyres. Part III: Randomized stochastic models. J Phys Oceanogr 33 (7): $1416-1445$

Brink KH, Beardsley RC, Niiler PP, Abbott M, Huyer A, Ramp S, Stanton T, Stuart D (1991) Statistical properties of near-surface flow in the California coastal transition zone. J Geophys Res 96 (C8): 14693

Castanedo S, Medina R, Losada IJ, Vidal C, Méndez FJ, Osorio A, Juanes JA, Puente A (2006) The Prestige oil spill in Cantabria (Bay of Biscay). Part I: operational forecasting system for quick response, risk assessment, and protection of natural resources. J Coast Res 22(6):1474-1489

Colin de Verdiere A (1983) Lagrangian eddy statistics from surface drifters in the eastern North Atlantic. J Mar Res 41(3):375-398

Coppini G, De Dominicis M, Zodiatis G, Lardner R, Pinardi N, Santoleri R, Colella S et al (2010) Hindcast of oil spill pollution during the Lebanon Crisis, July-August 2006. Mar Pollut Bull 62:140-153

Davis RE (1983) Oceanic property transport, Lagrangian particle statistics, and their prediction. J Mar Res 41(1):163-194

Davis RE (1985) Drifter observations of coastal surface currents during CODE: the method and descriptive view. J Geophys Res 90 (C3):4741-4755

Davis RE (1987) Modeling eddy transport of passive tracers. J Mar Res 45(3):635-666

Dobricic S, Pinardi N (2008) An oceanographic three-dimensional assimilation scheme. Ocean Model 22:89-105

Döös K, Rupolo V, Brodeau L (2011) Dispersion of surface drifters and model-simulated trajectories. Ocean Model 39:301-310

Fabbroni N (2009) Numerical simulations of passive tracers dispersion in the Sea. Ph.D. Thesis, University of Bologna

Falco P, Griffa A, Poulain P-M, Zambianchi E (2000) Transport properties in the Adriatic Sea as deduced from drifter data. J Phys Oceanogr 30(8):2055-2071

Figueroa HA, Olson DB (1989) Lagrangian statistics in the South Atlantic as derived from SOS and FGGE drifters. J Mar Res 47 (3):525-546

Griffa A (1996) Applications of stochastic particle models to oceanographic problems. In: Adler R et al. (eds) Stochastic modelling in physical oceanography, Birkhauser Boston, pp 113-140

Grilli F, Pinardi N (1998) The computation of Rossby radii of deformation for the Mediterranean Sea. MTP news 6(4)

Hunter JR, Craig PD, Phillips HE (1993) On the use of random walk models with spatially variable diffusivity. J Comp Physiol 106 (2):366-376

Koszalka IM, LaCasce JH (2010) Lagrangian analysis by clustering. Ocean Dyn 60(4):957-972 
Krauss W, Boning CW (1987) Lagrangian properties of eddy fields in the northern North Atlantic as deduced from satellite-tracked buoys. J Mar Res 45(2):259-291

LaCasce JH (2008) Statistics from Lagrangian observations. Prog Oceanogr 77(1):1-29

Maurizi A, Griffa A, Poulain P-M, Tampieri F (2004) Lagrangian turbulence in the Adriatic Sea as computed from drifter data: Effects of inhomogeneity and nonstationarity. J Geophys Res 109(C4):C04010

Millot C (1991) Mesoscale and seasonal variabilities of the circulation in the western Mediterranean. Dyn Atmos Ocean 15(3-5):179-214

Monti P, Leuzzi G (2010) Lagrangian models of dispersion in marine environment. Environ Fluid Mech 10(6):637-656

Oddo P, Adani M, Pinardi N, Fratianni C, Tonani M, Pettenuzzo D et al (2009) A nested Atlantic-Mediterranean Sea general circulation model for operational forecasting. Ocean Sci 5:461-473

Paschini E, Artegiani A, Pinardi N (1993) The mesoscale eddy field of the Middle Adriatic Sea during fall 1988. Deep Sea Res Part I Oceanogr Res Pap 40(7):1365-1377

Pinardi N, Coppini G (2010) Operational oceanography in the Mediterranean Sea: the second stage of development

Pinardi N, Korres G, Lascaratos A, Roussenov V, Stanev E (1997) Numerical simulation of the interannual variability of the Mediterranean Sea upper ocean circulation. Geophys Res Lett 24(4):425-428

Pinardi N, Allen I, Demirov E, De Mey P, Korres G, Lascaratos A et al (2003) The Mediterranean ocean forecasting system: first phase of implementation (1998-2001). In Annales Geophysicae European Geophysicae-European Geophysical Society. pagg. 3-20

Poulain P-M (2001) Adriatic Sea surface circulation as derived from drifter data between 1990 and 1999. J Mar Syst 29(1-4):3-32

Poulain P-M, Niiler PP (1989) Statistical analysis of the surface circulation in the California Current System using satellite-tracked drifters. J Phys Oceanogr 19(10):1588-1603

Poulain P-M, Zambianchi E (2007) Surface circulation in the central Mediterranean Sea as deduced from Lagrangian drifters in the 1990s. Cont Shelf Res 27(7):981-1001
Poulain P-M, Gerin R, Rixen M, Zanasca P, Teixeira J, Griffa A, Molcard A, De Marte M, Pinardi N (2012) Aspects of the surface circulation in the Liguro-Provencal basin and Gulf of Lion as observed by satellite-tracked drifters (2007-2009). Bollettino di Geofisica Teorica ed Applicata 53(2):261-279

Rupolo V (2007) A Lagrangian-based approach for determining trajectories taxonomy and turbulence regimes. J Phys Oceanogr 37(6):1584-1609

Sallée JB, Speer K, Morrow R, Lumpkin R (2008) An estimate of Lagrangian eddy statistics and diffusion in the mixed layer of the Southern Ocean. J Mar Res 66(4):441-463. doi:10.1357/ 002224008787157458

Swenson MS, Niiler PP (1996) Statistical analysis of the surface circulation. J Geophys Res 101(C10):22-631

Taylor GI (1921) Diffusion by continuous movements. Proc Lond Math Soc 20:196-212. doi:10.1112/plms/s2-20.1.196

Tonani M, Pinardi N, Dobricic S, Pujol I, Fratianni C (2008) A highresolution free-surface model of the Mediterranean Sea. Ocean Sci 4(1):1-14

Ursella L, Barbanti R, Poulain P-M (2004) DOLCEVITA drifter program: Rapporto tecnico finale. Tech. Report. 77/2004/OGA/30. OGS, Trieste

Ursella L, Poulain P-M, Signell RP (2006) Surface drifter derived circulation in the northern and middle Adriatic Sea: response to wind regime and season. J Geophys Res 111(C3):C03S04

Veneziani M, Griffa A, Reynolds AM, Mariano AJ (2004) Oceanic turbulence and stochastic models from subsurface Lagrangian data for the Northwest Atlantic Ocean. J Phys Oceanogr 34(8):1884-1906

Zambianchi E, Griffa A (1994) Effects of finite scales of turbulence on dispersion estimates. J Mar Res 52(1):129-148

Zang XY, Wunsch C (2001) Spectral description of low-frequency oceanic variability. J Phys Oceanogr 31(10):3073-3095. doi:10.1175/ 1520-0485(2001)031<3073:SDOLFO $>2.0 . C O ; 2$

Zhang HM, Prater MD, Rossby HT (2001) Isopycnal Lagrangian statistics from the North Atlantic Current RAFOS float observations. J Geophys Res 106(C7):13817-13836 